УДК 811.112.2’373: 811.16’373

DOI: $10.24144 / 2617-3921.2019 .17 .51-59$

Myroslava Ladtschenko Dozentin Doktor des Lehrstuhls für deutsche Philologie der Nationaluniversität Uschhhorod orcid.org/0000-0002-4007-5467 Uschhorod, Ukraine, + 38(050) 23094 44, miroslava.ladchenko@uzhnu.edu.ua

\title{
Deutsche Wortbildung von der Lautnachahmung der Tiere und Vögel
}

Анотація. Особливий шлях розвитку словника - це утворення звуконаслідувальних слів, а також слів, побудованих на основі наслідування звуків, так чи інакше зв'язаних з даними явищами. Звуконаслідування - ие звуковідтворення, або ономатопея - звук, імітація реальних явищ. Об'єктивною основою ономатопеї у будь-якій мові світу $\epsilon$ позамовне звучання. В основі ономатопів та їх похідних лежить наслідування людиною тих чи інших звуків живої та неживої природи в результаті пізнання нею навколишнього світу. Ономатопи - ие самостійні слова, які є основою для словотворення інших частин мови. Найближчими похідними від ономатопів 
є звуконаслідувальні дієслова. $У$ даній статті досліджуються ономатопоетичні дієслова та іменники, утворені від звуконаслідування тварин і птахів. Ця лексика має спільну ознаку за звучанням, тобто вона утворена шляхом наслідування людиною звуків тварин та птахів. Вивчення иієї лексики має велике значення для дослідження німецького словотворення.

Ключові слова: ономатопоетика, словниковий склад, вид словотворення, звуки, позамовне звучання.

Abstract. A specific way of vocabulary enrichment is a formation of sound imitating words and relating phenomena. Sound imitation or onomatopoeia is a sound or an imitation of real phenomena. A basis of onomatopoeia in any language is an extralinguistic sounding. Onomatopes and their derivatives are based on a human imitation of sounds, produced by animate nature and inanimate objects, while perceiving the reality. Onomatopes are independent words that serve the basis of words formation that belong to different parts of speech. Onomatopoeic verbs are proved to be their nearest derivatives. The present article deals with the study of onomatopoeic verbs and nouns, formed by means of imitating animals and birds sounds. The common feature of these words is the fact that they are produced by imitation. The perspectives of this research seem to be tightly connected with the significance of onomatopoeia in the study of German word-formation.

Keywords: onomatopoetics, word stock, a mode of word formation, sounds, extralinguistic sounding.

Einleitung. Der vorliegende Artikel ist einer der Wortbildungsarten des deutschen Wortschatzes gewidmet. Das ist die Lautnachahmung oder Onomatopöie. Diese Wortbildungsart ist meistens für die Verben und Substantive kennzeichnend, die von den Lauten der Tiere, Vögel, Menschen, der Gegenstände und Erscheinungen der Umwelt stammen. Der lautmalenden Lexik ist die direkte natürliche Verbindung zwischen der Bedeutung und Lautung eigen.

In der Sprachwissenschaft gibt es wenige Publikationen, in denen die Wortbildung der lautnachahmenden Wörter erforscht werden. Über die deutsche Lautmalerei schreibt in seiner Monographie B.I. Hinka [4]. I.A. Skolotova behandelt lautnachahmende Verben im Russischen [16]. J.V. JussypJakymowytsch schrieb eine Reihe von wissenschaftlichen Artikeln über die Onomatopoetika in den Mundarten der Karpaten und in den slawischen Sprachen [17]. Von der Autorin dieser Abhandlung sind einige Artikel verfasst, in denen allgemeine Probleme der Wortbildung in der deutschen Önomatopöie sowie lautmalende Verben und Substantive behandelt werden $[5 ; 6 ; 7 ; 8]$. Es gibt auch konfrontative Erforschungen über die Lautmalerei anhand verschiedener Sprachen. H.H. Bielfeldt erforscht die Lautmalerei im Deutschen und Sorbischen [1]. In den Publikationen von M.M. Ladtschenko und J.V. Jussyp-Jakymowytsch werden onomatopoetische Verben im Deutschen und in den slawischen Sprachen 
untersucht und verglichen $[12 ; 13 ; 14]$. Im Artikel von M. Ladtschenko und E. Vaschki werden onomatopoetische Verben des Sprechens im Deutschen und Ungarischen behandelt [11]. Die Untersuchung von I.O. Hazenko stellt die konfrontative Analyse der lautmalenden Wörter im Ukrainischen, Russischen und Englischen dar [10].

Man kann also konstatieren, dass diese linguistische Erscheinung in vielen Sprachen fixiert ist und universellen Charakter hat. Die meisten Linguisten sind der Meinung, dass zwischen onomatopoetischen Elementen in verschiedenen Sprachen eine auffallende Ähnlichkeit vorhanden ist. Ihr Grund besteht darin, dass die objektive Grundlage einer onomatopoetischen Einheit in allen Sprachen der Welt gleich ist. Das ist die außersprachliche Lautung, die Nachahmung der Laute der Umwelt. In allen Sprachen entstehen Lautnachahmungen im gleichen Bedeutungsbereich - des Geschreis, Geräusches, Schlages, Knarrens usw. [13, S. 98]. Die nächste Besonderheit der Onomatopoetika ist es, dass sie immer konkrete Bedeutungen wiedergeben, weil sie bestimmte konkrete Lautungen nennen. Die lautlichen Hüllen der Lautnachahmungen sind mit entsprechenden Erscheinungen der objektiven Wirklichkeit durch ihre Bedeutungen verbunden, die immer konkret sind. Diese Besonderheit ist den Lautnachahmungen der meisten Sprachen der Welt eigen. Es ist damit verbunden, dass die Lautnachahmungen nicht nur phonetisch sondern auch semantisch motiviert sind [17, S. 4]. Deswegen kann man behaupten, dass die Onomatopöie eine universelle linguistische Erscheinung ist. Aber in jeder Sprache hat diese Erscheinung bestimmte Besonderheiten.

Es ist aber auch zu bemerken, dass die Wortbildungsprozesse der deutschen lautmalenden Lexik und ihre Semantik ganz wenig erforscht sind.

Das Thema dieser Abhandlung betrifft deutsche lautmalende Verben, die von der Lautmalerei der Tiere und Vögel gebildet werden. Das Ziel der Erforschung ist es, wortbildende, grammatische und semantische Besonderheiten dieser Verben zu untersuchen. Die Aktualität des Forschungsthemas basiert darauf, dass der Wortbildung und dem Gebrauch der onomatopoetischen Lexik bestimmte grammatische, wortbildende und semantische Besonderheiten eigen sind, die forschungswert sind. Es sei auch zu betonen, dass es keine spezielle Erforschung der von den Tieren und Vögeln stammenden Lexik gibt. Somit gilt diese Erforschung als ein Teil des von der Autorin erforschten Themas.

Material und Untersuchungsmethoden. Das Forschungsobjekt ist deutsche Wortbildung. Der Gegenstand der Erforschung sind die Onomatopoetika und die davon gebildeten onomatopoetischen Verben und Substantive aus dem deutsch-ukrainischen Wörterbuch von V. Müller und dem deutschen Universalwörterbuch Duden. Bei der Untersuchung des Stoffes wurden solche Verfahren der wissenschaftlichen Forschung wie die Methoden des Recherchierens, Bearbeitens und der Analyse des Stoffes wie auch statistische Angaben verwendet.

Resultate und Diskussion. Man bestimmt die Onomatopöie als marginale linguistische Erscheinung, deren Grundlage die außersprachliche Lautung ist [17, 
S. 4]. Die meisten Sprachforscher behaupten, dass das eine absolute Erscheinung ist, weil sie in allen Sprachen der Welt vorhanden ist. Die außersprachliche Lautung ist also die objektive Grundlage der onomatopoetischen Wörter. $\mathrm{Zu}$ Grunde der lautmalenden Wörter liegt die Nachahmung der Laute der lebendigen und unlebendigen Natur im Resultat der Umwelterkenntnis.

In der Sprachwissenschaft gibt es verschiedene Termini zur Bezeichnung dieser linguistischen Erscheinung: Klangmalerei, Lautmalerei, Lautnachahmung, Schallnachahmung, Onomatopöie. Infolge der Lautnachahmung entsteht das Onomatopoetikon, das nach dem Duden-Wörterbuch „klangnachahmendes, lautmalendes Wort" ist [3, S. 1296]. Je nach den Lauten, die sie nachahmen, unterscheidet man drei Gruppen von Onomatopoetika [9]:

a) Menschliche Laute - äh, eh (beim Sprechen zögern), bäää (weinen), haha(ha), hähä(hä), hehe(he), hachachach, hihi (lachen), hatschi oder hatzi (niesen), hick (aufstoßen), uff (schnaufen), pfui (ausspeien), (h)uah (gähnen), $h(e) m$ (räuspern), hopp, hops, hoppla, hopsa (springen), trallalal trallala (beim Singen ohne Worte).

b) Tierische Laute - muh (Rind), mäh (Schaf), meck (Ziege), wau (Hund), iah (Esel), miau (Katze), kikeriki (Hahn), gack (Huhn), quiek (Ferkel), quak (Frosch), piep (Vogel, Maus), summ (Biene), tirili (Lerche), kuckuck (Kuckuck), krah (Rabe, Krähe), tschilp (Sperling).

c) Andere Laute - ticktack (Ticken der Uhr); bum, bum (Schlagen); trara, tätärätätä, schnedderengteng (Horn- oder Trompetensignal); dideldum, dideldumdei (Musik); piff, paff, tack, tack, tack, peng, peng (Schießen); bim, bam (Läuten), klingelingeling, kling, klang, bing (helles Klingen) usw.

Die Grundlage für die Bildung der onomatopoetischen Lexik sind Onomatopoetika. Infolge der historischen Entwicklung der Wörter und des Wortwandels sind sie für die Mehrheit der onomatopoetischen Lexik nicht festgestellt. In der Linguistik gibt es keine einheitliche Meinung hinsichtlich der Onomatopoetika.

Man muss auch betonen, dass die meisten Sprachforscher diese Onomatopoetika traditionell $\mathrm{zu}$ den Interjektionen zählen. Gerade diese Bezeichnung kann man im Lexikon der Sprachwissenschaft und im DudenWörterbuch und finden [2;3]. In der vorliegenden Publikation wird die Meinung jener Linguisten geteilt, die diese Wörter als Onomatopoetika bezeichnen [10; 17]. Infolgedessen werden sie als eine besondere selbstständige Wortart betrachtet.

Es wurden alle im Duden-Wörterbuch vorhandenen Onomatopoetika (gesamt 28 Einheiten) fixiert, von denen meistens Verben und auch Substantive gebildet werden. Es gibt auch lautmalende Adjektive, die aber zum Forschungsobjekt der vorliegenden Abhandlung nicht gehören. Die Bedeutungen sind dem Duden-Wörterbuch entnommen. Die Onomatopoetika sind in drei Gruppen unterteilt. Sie umfassen sowohl Onomatopoetika als auch die davon stammenden Verben. Die meisten Onomatopoetika bezeichnen die Laute und/oder 
Töne, die von den Tieren oder Vögeln hervorgerufen werden. Es können auch die Geräusche fliegender Insekten oder trappelnder Schritte oder Pferdehufe sein.

Zur ersten Gruppe gehören diejenigen, die von der Lautmalerei der Tiere kommen. Diese Gruppe ist die größte unter allen drei. Dazu gehören:

bäh - für das Blöken des Schafes; bähen (бекати);

blök - für das Blöken von Schafen; blöken, bläken (мукати, бекати);

bölk - für das Blöken von Rindern und Schafen; bölken (мукати, бекати)

iah - für den Schrei des Esels; iahen (кричати, ревіти (про осла); (рохкати);

grunz - für den Laut bestimmter Tiere, besonders Schweine; grunzen

meck - für das Meckern der Ziegen; meckern (мекати, бекати);

mäh - für das Blöken von Schafen; mähen (бекати);

miau - für den Laut der Katze; miauen (нявкати);

muh - für das Brüllen des Rindes; muhen (мукати (про корову);

quiek - für den Laut der Ferkel/ Schweine; quieken/quieksen, quietschen (пищати, верещати);

tapp/ trapp - für das Geräusch trappelnder Schritte oder Pferdehufe;

tapern (невпевнено рухатися); tapsen (розм. важко ступати); traben (повільним темпом бігти); trampeln (тупати ногами); trappeln (тупати); trapsen (розм. іти важкими кроками).

wau - für das Bellen des Hundes;

wieh - für den Laut des Pferdes; wiehern (іржати);

Die nächste Gruppe zählt die Onomatopoetika, die von der Lautmalerei der Vögel kommen. Das sind die folgenden lautnachahmenden Wörter:

gack/gacks - für das Gackern des Haushuhns; gackeln / gackern/ gacksen (кудкудакати);

gluck - für das Glucken der Henne glucken (кудкудакати) / glucksen (клекотати; кудкудакати (про квочку);

kikeriki - für den Ruf des Hahns;

kuckuck - für das Rufen des Kuckucks;

krah - für das Krähen der Rabe und Krähe; krähen (крякати);

summ - für das Geräusch fliegender Insekten, besonders Bienen; summen (дзижчати, гудіти); птахів);

tirili - von Vögeln, besonders Lerchen; tirilieren (співати, свистіти (про

tschilp - für das Geräusch des Sperlings; tschilpen (цвірінчати);

tucktuck - für den Lockruf der Hühner; tиckern (стукати);

zilpzalp - für den Ruf der Vögel;

zirp - für feine, helle Töne, besonders einiger Vögel (Grillen und Heimchen); zirpen (стрекотати, цвірінчати);

zwitsch - für den Ton bestimmter Vögel; zwitschern (щебетати, цвірінчати); 
Zuletzt sei die kleinste Gruppe der Lexik zu nennen, zu der die Onomatopoetika sowohl von der Lautmalerei der Tiere als auch der Vögel gehören. Das sind:

piep/pips - für das Piepen junger Vögel auch bestimmter Kleintiere, Mäuse; piepen/piepsen (пищати, цвірінчати);

quak/quack - für den Laut der Frösche oder Enten; quaken (квакати, крякати); quäken (пищати, верещати); quackeln (розм. базікати);

zisch - für den Laut der Gans, der Schlange; zischen (сичати); zischeln (шепотіти, шушукатися).

Es hat sich herausgestellt, dass die meisten onomatopoetischen Verben von den entsprechenden Onomatopoetika mittels des Suffixes $-(e) n$ gebildet werden. Die Suffixe -el(n), -er(n) kommen seltener vor. Von einigen Onomatopoetika lassen sich keine entsprechenden Verben bilden, zum Beispiel: kikeriki, kuckuck, wau, zilpzalp.

Es gibt eine Reihe der von den Onomatopoetika der Tiere und Vögel stammende Substantive. Sie können bestimmte Tiere, Tätigkeiten und Personen (übertragene umgangssprachliche Bedeutungen) bezeichnen. Die folgenden Tiernamen werden von den Onomatopoetika gebildet:

die Glucke - die Henne (квочка), die Krähe - der Rabe (ворона), der Kuckuck - Vogel mit braungrauem Gefieder (зозуля), das Kücken/Küken - junges Geflügel, kleines Kind (курча; мале дитя), der Kuckuck (зозуля), der Piepvogel kleiner Vogel (мала пташка); die Trappe (дрохва), die Wutz (свиня, порося), der Zilpzalp - der Singvogel (співочий птах), die Zirpe (цвіркун, коник).

Onomatopoetika werden auch in der Kindersprache zur Bezeichnung der Tiere verwendet, wie z.B.:

der Kikeriki - der Hahn (півень), der Quaker - der Frosch (жаба), der Piepvogel - kleiner Vogel (мала пташка), der Wauwau - der Hund (собака).

Was die von den Onomatopoetika gebildeten Substantive angeht, so lassen sich einige Wortbildungswege aussondern. Es gibt die Substantive, die mithilfe der Substantivierung des Onomatopoetikumstamms gebildet sind. Sie sind also reine Lautnachahmungen verschiedener Laute, Töne und Geräusche der Tiere. Diese Substantive können männliches oder sächliches Geschlecht haben. Das sind die nächsten Beispiele:

der Piep/Pieps - feiner, hoher Pfeifton (писк, цвірінькання), der Sums unnötiges Gerede (шум, галас), das Kikeriki - Ruf des Hahns (крик півня); das Tirili - das Tirili der Lerche (спів, свист жайворонка), der Zisch - (сичання, шипіння).

Natürlich kann man alle Verben substantivieren, weil diese Wortbildungsart als eine der charakteristischen im Deutschen gilt: das Blöken, das Mähen, das Miauen, das Meckern, das Traben usw.

Die Bildung der abgeleiteten Substantive mittels des Präfixes ge- und des Suffixes 
-e (-el, -er) oder nur mit dem Präfix ge- ohne Suffix ist sehr produktiv. Es wird betont, dass diese Wortbildungsart eine der produktivsten sei [8, S. 90]. Das betrifft insbesondere Umgangssubstantive, die größtenteils übertragene Bedeutungen besitzen. Alle diese Substantive sind sächlichen Geschlechts. Semantisch sind sie oft synonymisch mit den substantivierten Infinitiven. Es gibt zwei Varianten dieser Ableitungen. Hier sind die Varianten mit dem Suffix und ohne Suffix möglich:

das Geblök/Geblöke, das Gemecker / Gemeckere (бурчання, скиглення), das Gequake (квакання; невпинне базікання), das Gequiekel Gequitsche (верещання, пищання), das Gesumm/ Gesumme (дзижчання, шум), das Getrampel/ Getrappel (тупіт; тупотіння), das Gezirp/Gezirpe (цвірінкання, скрекотіння), Gezisch / Gezische / Gezischel (перешіптування, шушукання), das Gezwitscher (щебет, щебетання, цвірінькання).

Abgeleitete Substantive mit dem Suffix - $e i$ haben meistens auch übertragene Semantik und gehören zur deutschen Umgangssprache, wie zum Beispiel:

die Gackelei/ Gackerei - fortwährendes Gackeln (кудкудакання); die Meckerei (бурчання, скиглення); die Quackelei - die Quatschelei (балаканина, дурниця); die Zischelei - dauerndes Zischeln (розм. перешіптування, шушукання).

Es gibt Substantive männlichen Geschlechts, die mittels des Suffixes -er gebildet werden:

der Meckerer - jmd., der ständig meckert; Meckerer (причепа), der Pieper / Piepser - feiner, hoher Pfeifton (писк, цвірінькання), der Summer (зумер).

Es werden auch Komposita mit der lautmalenden Komponente gebildet, die von den Onomatopoetika, Verbstämmen oder lautmalenden Substantiven stammen. Man kann die nächsten Beispiele anführen:

das Kuckucksei - Ei eines Kuckucks; Kind eines anderen Vaters (яйце зозулі; розм. дитина від іншого батька); der Meckerfritze - jmd., der ständig meckert; Meckerer (причепа), Meckerliese/ Meckerziege - weibliche Person, die ständig meckert; Meckerin (жінка, яка постійно бурчить), die Quakente - die Ente (качка) der Quakfrosch - der Frosch (жаба), der Piepmatz - kleiner Vogel (мала пташка), der Summton - summender Ton (mеx. сигнал зумера), das Trampeltier - ungeschickter Mensch (розм. незграбна людина), der Zischlaut Sibilant (шиплячий звук).

Schlussfolgerungen. Infolge der durchgeführten Erforschung der Wortbildung der Verben und Substantive, die von der Lautmalerei der Tiere und Vögel stammen, lassen sich die folgenden Schlussfolgerungen ziehen:

1. Zu Grunde der lautmalenden Wörter liegt die Nachahmung der Laute der lebendigen und unlebendigen Natur im Resultat der Umwelterkenntnis. Durch die Lautnachahmung entsteht ein Schallwort oder Onomatopoetikon. Als Wortart werden Onomatopoetika meistens oft unter den Interjektionen behandelt. Aber auch andere Wortarten enthalten Onomatopoetika, zum Beispiel, Substantive und Verben. 
2. In der Linguistik gibt es keine einheitliche Meinung hinsichtlich der Onomatopoetika. Die meisten Sprachforscher zählen sie zu den Interjektionen. In dieser Erforschung wird die Auffassung derjenigen Autoren geteilt, die Onomatopoetika als eine besondere selbstständige Wortart betrachten. Infolge der historischen Entwicklung der Wörter und des Wortwandels sind Onomatopoetika für die Mehrheit der onomatopoetischen Lexik nicht feststellbar, weil ihre Abstammung verdunkelt ist.

3. Es wurden insgesamt onomatopoetische Verben und Substantive analysiert, die von 27 Onomatopoetika gebildet werden. Die Onomatopoetika bezeichnen die Laute und/oder Töne, die von den Tieren oder Vögeln ausgestossen werden. Darunter gibt es auch die Geräusche fliegender Insekten oder trappelnder Schritte oder Pferdehufe. Die Onomatopoetika sind in drei Gruppen gegliedert: a/ Onomatopoetika kommen von der Lautmalerei der Tiere; b/ sie stammen von der Lautmalerei der Vögel; c/ sie kommen von der Lautmalerei der Tiere und Vögel.

4. Die meisten Verben werden von den entsprechenden Onomatopoetika mittels des Suffixes -en, seltener -eln, -ern gebildet. Von einigen Onomatopoetika lassen sich keine Verben bilden.

5. Die Wortbildung der Substantive der onomatopoetischen Herkunft ist sehr unterschiedlich. Sie können von den Onomatopoetika und onomatopoetischen Verben gebildet werden. Die Substantive können bestimmte Tiere, Tätigkeiten und Personen (übertragene umgangssprachliche Bedeutungen) bezeichnen.

6. Man kann die folgenden Wortbildungsarten der Substantive nennen: Substantivierung der Onomatopoetika und Infinitive; Bildung der abgeleiteten Substantive mittels des Präfixes $g e$ - und Suffixes -e (-el, -er) oder nur mit dem Präfix $g e$ - ohne Suffix; Bildung der abgeleiteten Substantive mit dem Suffix -ei; Komposita mit der lautmalenden Komponente.

7. Die von den Onomatopoetika stammenden Verben und Substantive besitzen oft übertragene expressive Bedeutungen, dank denen sie zur deutschen Umgangssprache gehören.

\section{LITERATUR}

1. Bielfeldt H. H. Onomatopoetika im Sorbischen und Deutschen//Zeitschrift für Slavistik. 1982. N 3. S. 323-331.

2. Bußmann H. Lexikon der Sprachwissenschaft. Stuttgart: Alfred Kröner Verlag, 2002. $783 \mathrm{~S}$.

3. Duden. Deutsches Universalwörterbuch. Mannheim: Dudenverlag, 2011. $2112 \mathrm{~S}$.

4. Hinka B. I. Lexikologie der deutschen Sprache: Vorlesungen und Seminare. Навчальний посібник для студентів-германістів. Тернопіль: Редакційно-видавничий відділ Тернопільського національного педагогічного університету імені В.Гнатюка, 2005. 220 с. 
5. Ladtschenko M. Onomatopoetische Verben des Sprechens in der deutschen Umgangssprache// Germanistik in der Ukraine. 2011. Вип. 12. S. 109-112.

6. Ladtschenko M. Wortbildungsprozesse in der deutschen Onomatopöie// Сучасні дослідження з іноземної філології. 2014. Вип. 12. С. 101-105.

7. Ladtschenko M. Wortbildende und semantische Besonderheiten der deutschen onomatopoetischen Fortbewegungsverben//Сучасні дослідження з іноземної філологї̈. 2015. Вип. 13. С. 80-86.

8. Ladtschenko M. Deutsche Substantive onomatopoetischer Herkunft. Мова та культура: матеріали міжнар. наук.-практ. конференції (Одеса, 20-21 листопада 2015 р.). Одеса: Міжнародний гуманітарний університет, 2015. C. 89-92.

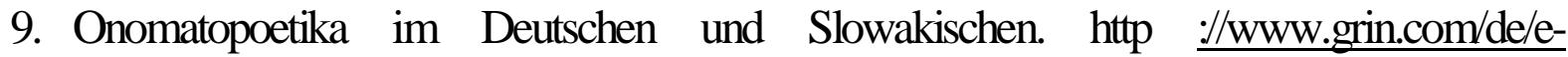
book/208976/

10.Гаценко І.О.Типологічні особливості звуконаслідувальних слів (на матеріалі української, російської та англійської мов): автореф. дис. ... канд. філол. наук: Київ, 2003. 19 с.

11.Ладченко М., Вашкі Е. Контрастивний аналіз відономатопоетичних дієслів мовлення: на матеріалі німецької та угорської мов. Ужгород: Патент, 2010. С. 298-307.

12.Ладченко М.М., Юсип-Якимович Ю.В. Verba Dicendi: німецькослов'янські лексичні паралелі//Сучасні дослідження 3 іноземної філології. 2010. Вип. 8. С. 296-304.

13.Ладченко М.М., Юсип-Якимович Ю.В. Слов'яно-германські семантичні універсалії в галузі ономанопоетики// Studia Slovakistica. 2014. Вип. 14. С. 92-103.

14.Ладченко М.М., Юсип-Якимович Ю.В. Ономатопоетичні утворення як система універсалій в індоєвропейських та угро-фінських мовах// Acta Hungarica, 2018. Вип. 23. С. 189-201.

15.Мюллер В. Великий німецько-український словник. Київ: Чумацький шлях, 2005. $792 \mathrm{c}$.

16. Сколотова И. А. Глаголы, обозначающие сравнение человеческой речи с другими звуками//Ученые зап. Горьковского пед. ин-та им. М. Горького. 1969. Вып. 95. С. 3-10.

17.Юсип-Якимович Ю. В. Ономатопоетика українських говорів Карпат: семантична, фонетична, словотвірна структура та похідність ономатопів. Ужгород: Гражда, 2007. 268 с. 